\title{
Factors affecting the Functional Independence Measure Gain of Patients with Stroke
}

\author{
Tuncay ÇAKIR, Rahime Nur SARIER, Şebnem KOLDAŞ DOĞAN, Naciye Füsun TORAMAN \\ Department Physical Medicine and Rehabilitation, Antalya Training and Research Hospital, Antalya, Turkey
}

\begin{abstract}
Objective: To investigate the effect of rehabilitation in patients admitted to our clinic after stroke on the latest situation.

Material and Methods: Medical records of 126 patients who were brought to the PMR Clinic at Antalya Education and Research Hospital between October 2010 and November 2011 and were hospitalized and received a rehabilitation program were evaluated retrospectively.

Patients were divided into the following groups according to etiology, ischemic and hemorrhagic; age, under and over $65 y e a r s$ of age; the time passed until the onset of rehabilitation, early ( $<3$ months) and late ( $\geq 3$ months); and by affected side, right and left. The functional status of patients at admission to our center, at discharge from our center, and the functional gains during hospitalization were evaluated by Functional Independence Measure (FIM), FIM gain, and FIM efficiency.

Results: Admission FIM values were found to be $73.2 \pm 29.1$ for patients with acute phase and $80.7 \pm 32.9$ for patients with chronic phase. There was no statistically significant difference between the two groups. Mean FIM gain was $17.7 \pm 18.2$ for patients with acute phase and $9.3 \pm 11.7$ for patients with chronic phase; FIM gain in patients with acute phase was statistically significant $(\mathrm{p}=0.02)$. FIM efficiency in patients with acute phase was statistically significant $(\mathrm{p}=0.03)$.

Conclusion: As a result, FIM gain and FIM efficiency in patients with acute phase were higher in patients with chronic phase in this retrospective study conducted in 126 hemiplegic patients. The early onset of rehabilitation will enable patients to perform more comfortable daily life activities and to achieve more functional gain.

Keywords: Stroke, rehabilitation, gain
\end{abstract}

\section{Introduction}

Stroke is the most common neurological problem in the world and located in the third place as a reason of death after heart disease and cancer (1). It also ranks first among the causes of disability and plays an important role in industrialized societies in terms of healthcare expenditures (2). It is a clinical syndrome characterized by rapid development of signs and symptoms of focal cerebral dysfunction without any apparent reason other than vascular causes leading to various deficiencies such as motor, sensory, emotional, mental, perception, visual field defects, intellectual, and speech disorders (3-6).

Ten percent of stroke patients recover spontaneously within the first month and $80 \%$ of patients are the candidates for rehabilitation (7). The other $10 \%$ of patients do not respond to treatment.

Functional recovery after stroke is closely related to age, etiology, and severity of neurologic deficit and localization. Gender and accompanying chronic systemic diseases increase the risk for stroke, but their contribution to functional recovery is con- 
troversial (8). Factors such as patient's education, motivation, and socioeconomic level may be important in recovery.

The onset time of rehabilitation after stroke is also important. The effectiveness of rehabilitation is further increased with early onset of therapy. Therefore, rehabilitation approaches should be initiated as soon as possible. Late-onset rehabilitation is considered to be indicative of a poor prognosis (9-11). The purpose of rehabilitation of stroke patients is to ensure that patient's gain optimal functional capacity and independence as soon as possible (12).

The aim of this study was to investigate the influence of factors such as age, gender, etiology, affected side, time to onset of rehabilitation, and length of stay at the hospital on functional recovery in patients with stroke.

\section{Material and Methods}

The method of study was designed as cross-sectional study. For this purpose, medical records of 126 patients who were brought to the Physical Medicine and Rehabilitation Clinic of Antalya Training and Research Hospital between October 2010 and November 2011 and were hospitalized and received rehabilitation were evaluated retrospectively.

Approval for the study was granted by committee of Antalya Training and Research Hospital and informed consent was obtained from all the study participants. The patients who were between 27 to 83 years of age, diagnosed by Computed Tomography (CT) or magnetic resonance (MR) imaging for the first time as having stroke due to ischemic or hemorrhagic lesion, and were hospitalized at our clinic and undergoing rehabilitation were included in the study. The patients with a previous history of stroke; who were diagnosed with psychiatric illness, uncontrolled hypertension, and decompensated cardiac insufficiency; and had lack of medical records were excluded from the study.

Age, gender, stroke etiology, affected side, dominant hand, time onset to admission interval, Functional Independence Measure (FIM) values before the onset of rehabilitation and at discharge, the total length of stay in the hospital, and spasticity levels were recorded.

Patients were divided into the following groups according to: etiology, ischemic and hemorrhagic; age, under and over the age of 65 years; the time passed until the onset of rehabilitation, early ( $<3$ months) and late ( $\geq 3$ months); and affected side, right and left. The functional status of patients at admission to our center, at discharge from our center, and the functional gains during hospitalization were evaluated by FIM, FIM gain, and FIM efficiency.

\section{Assessment scales}

Functional Independence Measure is divided into two submeasures, motor and cognitive FIM, evaluating six categories and a total of 18 activities determining the level of functional disability. The six categories include self-care (42 points), sphincter control (14 points), transportation (21 points), motion (14 points), communication (14 points), and social perception (21 points). A 7-point scale is used for each activity. The scores range from 18 to 126 (13). The adaptation of the Turkish version of FIM was done, and it was found to be reliable and valid (14).

Functional Independence Measure Gain: It is the difference between FIM scores of patients was recorded before the initiation of rehabilitation and at discharge.

Functional Independence Measure Efficiency: FIM efficiency was obtained by dividing FIM gain by the total length of hospital stay.

Modified Ashworth Scale: It has been assessed using Spasticity Modified Ashworth Scale. Muscle tone with this scale is evaluated with intensity ranging from 0 to 4 . Zero indicates normal muscle tone and 4 indicates rigid affected joints at flexion or extension (15).

Rehabilitation program: Stroke patients hospitalized in the Department of Physical Medicine and Rehabilitation are evaluated by the rehabilitation team and an appropriate treatment through a neurological rehabilitation program is planned and administered regularly during the stay in the hospital. Treatment protocol is followed under regular monitoring of physiological parameters such as blood pressure, heart rate, respiratory rate, and body temperature. The exercises were applied to all patients once a day for 5 days a week at an average of $1 \mathrm{~h}$ a day during the duration of hospital stay. Four physiotherapists trained on the Bobath approach, which is one of the neurophysiological approaches, implemented the rehabilitation program, and walking education. Exercises were in the following forms: for the upper extremity using a bed, shoulder elevation, scapular mobilization, elbow, and hand/wrist movements; for the lower extremity, pelvic rotation and pelvic elevation. The level of mobility of the patients in bed is advanced in the shortest period of time and the patient was gradually brought to the level of sitting. At the level of sitting, training for body balance, rotation, and weight transfer to the affected upper extremity. The development of sitting balance in the early period plays an important role in improvement. When the patient is appropriately balanced, hemodynamically and clinically, he/she was set on foot. First, weight transfer and balance training using a parallel bar is given to the patient who was set on foot, and then walking training was initiated.

\section{Statistical Analysis}

The data was analyzed using Statistical Package for the Social Sciences (SPSS Inc., Chicago, IL, USA) 16.0 software program. It was performed using the Kolmogorov-Smirnov test to determine whether the data showed normal distribution. The mean values for both groups were compared using Student's t test and Mann-Whitney $U$ test. Chi-square test was used to compare categorical variables. Pearson and Spearman correlation tests were used for correlation between variables. Statistical significance level was accepted as $p<0.05$.

\section{Results}

In this study, a total of 126 patients [59 (46.8\%) female and $67(53.1 \%)$ male] were included. The mean age of the patients was $62.0 \pm 12.2$ years. Female and male patients' mean 
Table 1. Demographic and clinical characteristics

\begin{tabular}{llcc} 
& & $\mathrm{N}$ & $\%$ \\
\hline Gender & Female/Male & $59 / 67$ & $46.8 / 53.1$ \\
Etiology & Ischemic/Hemorrhagic & $102 / 24$ & $80.9 / 19.0$ \\
Affected side & $\begin{array}{l}\text { Right hemiplegia/Left } \\
\text { hemiplegia }\end{array}$ & $62 / 64$ & $49.2 / 50.7$ \\
The time onset & Acute/Chronic & $63 / 63$ & $50 / 50$ \\
to admission & & \multicolumn{2}{c}{$\begin{array}{l}\text { Mean } \pm \text { standard } \\
\text { deviation }\end{array}$} \\
& & $62.0 \pm 12.2$ \\
Age & (Years) & $30.4 \pm 19.0$ \\
Length of & (Days) & & \\
hospital stay & & &
\end{tabular}

Table 2. Admission and discharge FIM values

\begin{tabular}{lcccc} 
& Admission FIM & $\mathbf{p}^{*}$ & Discharge FIM & $\mathbf{p}^{\mathbf{a}}$ \\
\hline Female & $78.2 \pm 30.3$ & & $90.2 \pm 30.2$ & \\
Male & $75.9 \pm 32.1$ & 0.688 & $90.9 \pm 28.4$ & 0.975 \\
$<65$ years & $83.0 \pm 32.9$ & & $95.6 \pm 29.9$ & \\
$\geq 65$ years & $70.3 \pm 27.8$ & 0.021 & $85.0 \pm 27.5$ & 0.009 \\
Ischemic & $78.0 \pm 31.7$ & & $92.09 \pm 28.92$ & \\
Hemorrhagic & $72.7 \pm 28.7$ & 0.458 & $84.25 \pm 30.06$ & 0.222 \\
Right hemiplegia & $70.4 \pm 30.3$ & & $86.9 \pm 29.5$ & \\
Left hemiplegia & $83.3 \pm 30.8$ & 0.019 & $94.1 \pm 28.6$ & 0.098 \\
Acute & $73.2 \pm 29.1$ & & $91.06 \pm 25.33$ & \\
Chronic & $80.7 \pm 32.9$ & 0.176 & $90.1 \pm 32.7$ & 0.650 \\
\hline
\end{tabular}

*Student's t-test, a Mann-Whitney U test. FIM: Functional Independence Measure

\begin{tabular}{|c|c|c|c|c|}
\hline & FIM Gain & p & FIM Efficiency & p \\
\hline Female & $11.7 \pm 13.1$ & & $0.48 \pm 0.50$ & \\
\hline Male & $15.1 \pm 17.1$ & 0.353 & $0.62 \pm 0.68$ & 0.278 \\
\hline$<65$ years & $12.6 \pm 17.0$ & & $0.49 \pm 0.58$ & \\
\hline$\geq 65$ years & $14.5 \pm 14.3$ & 0.178 & $0.62 \pm 0.63$ & 0.197 \\
\hline Ischemic & $13.9 \pm 16.6$ & & $0.57 \pm 0.64$ & \\
\hline Hemorrhagic & $12.0 \pm 11.6$ & 0.915 & $0.49 \pm 0.44$ & 0.965 \\
\hline Right hemiplegia & $16.5 \pm 18.1$ & & $0.65 \pm 0.67$ & \\
\hline Left hemiplegia & $10.7 \pm 12.6$ & 0.048 & $0.46 \pm 0.52$ & 0.062 \\
\hline Acute & $17.7 \pm 18.2$ & & $0.71 \pm 0.66$ & \\
\hline Chronic & $9.3 \pm 11.7$ & 0.001 & $0.39 \pm 0.50$ & 0.001 \\
\hline
\end{tabular}

Mann-Whitney U test. FIM: Functional Independence Measure

age were $62.5 \pm 12.4$ and $61.6 \pm 12.1$ years, respectively, and there was no statistically significant difference between two groups $(p=0.65)$.

Sixty-two patients had right hemiplagia and 64 had left hemiplegia. Eighty-nine percent $(n=102)$ of lesions were ischemic. The time onset to admission was $<3$ months in 63 patients
Table 4. The relationship of FIM efficiency and FIM gain with age, etiology, duration of illness, and duration of hospital stay

\begin{tabular}{lccccc} 
& \multicolumn{2}{c}{ FIM Gain } & & \multicolumn{2}{c}{ FIM Efficiency } \\
\cline { 2 - 3 } \cline { 5 - 6 } & $\mathbf{r}$ & $\mathbf{p}$ & & $\mathbf{r}$ & $\mathbf{p}$ \\
\hline Age $^{*}$ & -0.022 & 0.894 & & -0.050 & 0.760 \\
Etiology** $^{*}$ & -0.009 & 0.916 & & -0.004 & 0.965 \\
Duration of illness $^{* *}$ & -0.288 & 0.001 & & -0.286 & 0.001 \\
Duration of hospital stay $^{* *}$ & 0.437 & $<0.001$ & & -0.023 & 0.889 \\
FIM gain $^{* *}$ & & & & 0.904 & $<0.001$ \\
FIM efficiency $^{* *}$ & 0.904 & $<0.001$ & &
\end{tabular}

*Pearson Correlation test, ${ }^{*}$ Spearman Correlation test. FIM: Functional Independence Measure

and $>3$ months in 63 patients. Demographic and clinical characteristics of the patients are shown in Table 1.

No differences were found in age, etiology, hemiplegic side, the time passed until rehabilitation, and the dominant hand between female and male patients ( $p>0.05)$. FIM at admission was $78.2 \pm 30.3$ for females and $75.9 \pm 32.1$ for males. The patients showed a statistically significant improvement after treatment $(p<0.05)$, but there was no difference between male and female patients in terms of FIM gain and FIM efficiency.

Although FIM of patients with ischemia at admission was $78.0 \pm 31.7$, it was $72.7 \pm 28.7$ in patients with hemorrhagic lesions. Improvement was observed in both groups. FIM gain and FIM efficiency did not differ according to the etiology.

In the pretreatment evaluation of FIM in patients, it has been found that admission FIM scores of patients with left hemiplegia were significantly higher than admission FIM scores of those with right hemiplegia $(p=0.019)$. FIM gain was greater in the right-sided hemiplegic patients $(p=0.048)$. There was no statistically significant difference between the two groups in terms of FIM efficiency $(p=0.062)$.

Admission FIM values were found to be $73.2 \pm 29.1$ in patients with acute phase and $80.7 \pm 32.9$ in patients with chronic phase. There was no statistically significant difference between the two groups $(p=0.176)$. Mean FIM gain was $17.7 \pm 18.2$ for patients with acute phase and $9.3 \pm 11.7$ for patients with chronic phase; FIM gain and FIM efficiency in patients with acute phase were statistically significant $(p=0.001$ and $p=0.001$, respectively). The data according to the variants is shown in Table 2 and Table 3.

Functional Independence Measure gain and FIM efficiency were not related to age and etiology ( $p>0.05)$. There were weak negative correlations between FIM gain, FIM efficiency, and the duration of illness. If the duration of illness became longer, FIM gain $(r=-0.288, p=0.001)$ and FIM efficiency $(r=-0.286, p=0.001)$ were reduced. There was weak positive correlation between the duration of hospital stay and FIM gain but not with FIM efficiency. Additionally, a high correlation was detected between FIM gain and FIM efficiency $(r=0.904, p<0.001)$ (Table 4).

\section{Discussion}

Stroke is a significant health problem causing severe mental, physical, and spiritual pathologies in patients who survive. Nowa- 
days, the survival rate has increased with advances in diagnosis and treatment and $80 \%$ of patients are candidates of rehabilitation (7). The determination of the initial motor and functional status of the patients with rehabilitation potential is important in prognosis estimation and in determining the rehabilitation targets.

In our study, although the functional status at admission in female patients was better, there was no difference between genders in terms of FIM gain and FIM efficiency. Nevertheless, there are conflicting results in the literature on gender and its effect on functional improvement $(16-20,25,28)$. In a study by Hachisuka et al. (16), it has been found that although there was no significant difference in terms of motor function in stroke between female and male patients, FIM scores of male patients with stroke tended to be lower than those of female patients with stroke. The reason for this was considered that male patients have more attention and assistance from the people around them during activities of daily living. In the literature, the reason for poor functional status of female patients after stroke is related to having stroke at an older age than males (17). In our study, there was no significant difference between males and females in terms of the evaluation of discharge, and both female and male patients showed significant improvement after treatment. On admission, higher FIM values of female patients may have been associated with late hospital admission because female patients may show functional improvement until the start of rehabilitation.

Wyller et al. (18) evaluated the functional inadequacy of patients at 6 months post-stroke using the Barthel index and reported that females were worse in terms of functional improvement. Glader et al. (19) explained that the reason of functional inadequacy of females at 3 months post-stroke was the more advanced age compared to males and more risk factors. However, Ohwaki et al. (20) stated that there was no effect of gender on functional impairment in patients at 2 months post-stroke.

Age is an important risk factor for stroke. Approximately $70 \%$ of stroke survivors are over the age of 65 years. The incidence of stroke increases twice per decade after the age of 55 years (21). In our study, patients were divided into two groups according to age. Pretreatment and posttreatment FIM values of patients under the age of 65 years were higher than those of patients aged 65 years and above. However, there was no statistical significant difference in FIM gain and FIM efficiency between the patients aged $<65$ years and $>65$ years. Many studies have reported that age is an important factor for improvement (8). The formation of new neural connections and sinaptogenesis in the central nervous system tends to decrease because of aging. Therefore, increasing age is a risk factor for the return after stroke (22). Sputtitada et al. (23) accepted age as a strong indicator for functional recovery and determined showed that advanced age leads patients to more disabled status and has a negative impact on rehabilitation. In the study conducted by Lin et al., it has been reported that there was a negative correlation between discharge FIM scores and age (24). Eskiyurt et al. (25) reported that there was a negative correlation between patients' age and the total FIM score. Similarly, Hajek et al. (26) have also identified that patients at an advanced age have decreased cognitive abilities, with increasing age having a negative impact on functional recovery. In contrast to these studies, Wade et al. (27) reported that age was not predictive of functional development and that the best predictive factor for functional development was the initial functional status.

In our study, the etiology of stroke was evaluated and cerebral ischemia was found in 102 (80.9\%) patients and intracerebral hemorrhage in 24 patients (19.0\%). In the study conducted by Eskiyurt et al. (25), according to their etiologies, cerebral ischemic stroke, intracerebral hemorrhage, and subarachnoid hemorrhage were found in $66.3 \%, 20.7 \%$, and $1.6 \%$ of respectively among the patients. There is no difference between patients with hemorrhagic and ischemic stroke in terms of the scores of FIM gain and FIM efficiency and no relationship was found between FIM gain and etiology. This indicates that functional recovery in patients with stroke and improvement in ambulance was not affected by the etiology. Consistent with this study, Yıldız et al. (28) reported similar results. It has been reported in the study performed by Wade et al. (27) that the affected side did not affect the functional results of rehabilitation. Similarly Yıldız et al. (28) reported that there was no relationship between the affected side and the functional results. In our study, although admission and discharge FIM scores in patients with left hemiplegia were higher, FIM gain and FIM efficiency were higher in patients with right hemiplegia. The difference was found to be statistically significant $(p=0.04)$.

In the studies, there are contradictory findings between the hemisphere affected by lesion and the functional results. According to the study conducted by Macciocchi et al., lesions in the dominant hemisphere and those at the cortical level show better functional recovery. In the study conducted by Pantano et al., the correlation between whether the lesion is in the dominant hemisphere, the lesion size, and the location and the severity of the loss of motor function was not determined $(29,30)$.

The number of patients whose rehabilitation start time was shorther and longer than 3 months were equal. The baseline FIM values of patients whose treatment was initiated in the acute phase were lower than those of patients whose treatment was initiated in the chronic phase. This may be associated with the fact that the patients in the chronic phase applied by passing more pronounced healing process during the acute phase. But after rehabilitation, more improvements in FIM were found in acute-phase patients. In the same group, FIM gain and FIM efficiency were also found to be higher and the results were statistically significant. All patients have functional gains at the end of rehabilitation programs. The relationship between early rehabilitation and better functional recovery was shown by Paolucci et al. (31). They identified that the patients whose rehabilitation was initiated early were more successful in performing the activities of daily life and obtained better functional results compared with those whose rehabilitation was initiated late (20 days and more after stroke). As a result of the studies by Balcı et al. (32), it has been shown that early physiotherapy had a significant therapeutic effect on the patients' motor, balance, functional mobility, and independence functions. However, Eskiyurt et al. (25) reported that there was no difference between 
disease duration and FIM score. Similarly, Ay et al. (8) reported that the early onset of rehabilitation was not one of the factors affecting functional recovery. One of the main reasons for these different findings in these studies was the patient characteristics included in the study and differences in the methods. The heterogeneous population of stroke patients, variability in diagnosis, mixing of single and recurrent stroke, and combining patients in different time periods such as acute or chronic rehabilitation are frequently encountered problems in the studies. In addition, early physiotherapy in the stroke unit prevents systemic problems such as deep vein thrombosis, pulmonary embolism, joint contractures, pressure sores, and orthostatic blood pressure and provides a positive psychological contribution. Furthermore, early mobilization approaches have been reported in the literature as approaches that kept the patient more active in the home environment $(33,34)$.

In various studies, the duration of hospital stay was reported to be vary from 32 to 59 days (34-36). In our study, we found that the average duration of stay was 30.4 days. It has been found by Wang et al. (37) that the Barthel index score in patients with a short duration of hospitalization was higher. In our study, a positive correlation between the duration of hospital stay and FIM gain values and a negative correlation between the duration of hospital stay and FIM efficiency values were found; although the patient's functional recovery continued during the hospitalization, the density of gain decreased with the prolongation of the duration of hospital stay.

\section{Conclusion}

Functional Independence Measure gain and FIM efficiency in patients with acute phase were higher than those in patients with chronic phase in this retrospective study conducted in 126 hemiplegic patients. Early onset of rehabilitation will enable patients to perform more comfortable daily life activities and achieve more functional gain.

Ethics Committee Approval: Ethics committee approval was received for this study from the ethics committee of Antalya Training and Research Hospital (05.09.2013 / File Number :2013/125).

Informed Consent: Written informed consent was obtained from patients who participated in this study.

Peer-review: Externally peer-reviewed.

Author contributions: Concept - T.Ç.; Design - R.N.S.; Supervision - N.F.T.; Resource - Ş.K.D; Materials - T.Ç.; Data Collection and/or Processing - R.N.S.; Analysis and/or Interpretation - N.F.T.; Literature Search - Ş.K.D.; Writing - T.Ç, R.N.S.; Critical Reviews - N.F.T.; Other - T.Ç., R.N.S.

Acknowledgements: The authors thank to doctor Zuhal Arıca for her support to collect the data.

Conflict of Interest: No conflict of interest was declared by the authors.

Financial Disclosure: The authors declared that this study has received no financial support.

\section{References}

1. Özcan O. Hemipleji rehabilitasyonu. Oğuz H Editör. Tıbbi Rehabilitasyon. Istanbul: Nobel Tıp Kitabevleri; 1995:385-99.

2. Utku U. Inme Tanımı, Etyolojisi, Sınıflandırma ve Risk Faktörü. Türk Fiz Tip Derg 2007;53:1-3.

3. Calautti C, Leray F, Guincestre JY, Marie RM. Sequential activation brain mapping after subcortical stroke: Changes in hemispheric balance and recovery. Neuroreport 2001;12:3883-6. [CrossRef]

4. Ferrucci L, Bandinelli S, Guralnik JM, Lamponi M, Bertini C, Falchini $\mathrm{M}$, et al. Recovery of functional status after stroke. A postrehabilitation follow-up study. Stroke 1993;24:200-5. [CrossRef]

5. İstanbul üniversitesi İstanbul Tıp Fakültesi Temel ve Klinik Bilimler ders kitapları -Nöroloji-Nobel tıp kitapevi- 2004.s.193.

6. Yavuzer G, Sonel B, Tuncer S, Süldür N. Inmeli Hastalarda Üst Ekstremite ve El Fonksiyonlarının Değerlendirilmesi. Türk Fiz Tıp Derg 2001;47:38-43.

7. Doğan A, Nakipoğlu GF, Aslan DM, Kaya ZA, Özgirgin N. The rehabilitation results of hemiplegic patients. Turk J Med Sci 2004;34:385-9.

8. Ay S, Doğan ŞK, Evcik D. İnmeli Hastalarda Risk Faktörleri ve Fonksiyonel lyileşme Üzerine Etkileri. Yeni Tıp Dergisi 2009;26:37-41.

9. Young JA, Tolentino M. Neuroplasticity and its applications for rehabilitation. Am J Ther 2011;18:70-80. [CrossRef]

10. Maulden SA, Gassaway J, Horn SD, Smout RH, Dejong G. Timing of initiation of rehabilitation after stroke. Arch Phys Med Rehabil 2005;86:34-40. [CrossRef]

11. Sze KH, Wong E, Or KH, Lum CM, Woo J. Factors predicting stroke disability at discharge: A study of 793 Chinese. Arch Phys Med Rehabil 2000;81:876-80. [CrossRef]

12. Lindmark $B$, Hamrin E. Evaluation of functional capacity after stroke as a basis for active intervention. Presentation of a modified chart for motor capacity assessment and its reliability. Scand J Rehabil Med 1988;20:103-9.

13. Dromerick AW, Edwards DF, Diringer MN. Sensitivity to changes in disability after stroke: A comparison of four scales useful in clinical trials. J Rehabil Res Dev 2003;40:1-8. [CrossRef]

14. Küçükdeveci AA, Yavuzer G, Elhan AH, Sonel B. Adaptation of the functional independence measure for use in Turkey. Clin Rehabil 2001;15:311-8. [CrossRef]

15. Bohannon RW, Smith MB. Interrater reliability on a modified Ashworth scale of muscle spasticity. Phys Ther 1987;67:206-7.

16. Hachisuka K, Tsutsui Y, Furusawa K, Ogata H. Gender differences in disability and lifestyle among community-dwelling elderly stroke patients in Kitakyushu, Japan. Arch Phys Med Rehabil 1998;79:9981002. [CrossRef]

17. Kim JS, Lee KB, Roh H, Ahn MY, Hwang HW. Gender Differences in the Functional Recovery after Acute Stroke. J Clin Neurol 2010;6:183-8. [CrossRef]

18. Wyller TB, Sodring KM, Sveen U, Ljunggren AE, Bautz-Holter E. Are there gender differences in functional outcome after stroke? Clin Rehabil 1997;11:171-9. [CrossRef]

19. Glader EL, Stegmayr B, Norrving B, Terent A. Sex differences in management and outcome after stroke: a Swedish national perspective. Stroke 2003;34:1970-5. [CrossRef]

20. Ohwaki K, Hashimoto H, Sato M, Tokuda H. Gender and family composition related to discharge destination and length of hospital stay after acute stroke. Tohoku J Exp Med 2005;207:325-32. [CrossRef]

21. Brandstater ME. Inme rehabilitasyonu In: Delisa AJ (Arasıl T çeviri editörü) Fiziksel Tıp ve Rehabilitasyon Illkeler ve Uygulamalar. Ankara: Güneş Tıp Kitapevler 2007.p.1655-76. 
22. Teasell R, Bayona N, Salter K, Hellings C, Bitensky J. Progress in Clinical Neurosciences: Stroke Recovery and Rehabilitation, Can J Neurol Sci 2006;33:357-64. [CrossRef]

23. Sputtitada A, Aksaranugrahan S, Granger CV, Sankaew M. Results of stroke rehabilitation in Thailand. Disabil Rehabil 2003;25:1140-5. [CrossRef]

24. Lin JH, Hsiao SF, Chang CM, Huang MH, Liu CK, Lin YT. Factors influencing functional independence outcome in stroke patients after rehabilitation. Kaohsiung J Med Sci 2000;16:351-9.

25. Eskiyurt N, Yalıman A, Vural M, Kızıltaş $H$, Bölüknaşı N, Çeşme $F$. Inmeli olguların özellikleri ve fonksiyonel durum sonuçları. İst Tıp Fak Derg 2005;68:71-7.

26. Hajek VE, Gagnon S, Ruderman JE. Cognitive and functional assessments of stroke patients: an analysis of their relation. Arch Phys Med Rehabil 1997;78:1331-7. [CrossRef]

27. Wade DT, Hewer RL, Wood VA. Stroke; The influence of age upon outcome. Age Aging 1984;13:357-62. [CrossRef]

28. Yıldız N, Şanal E, Sarsan A, Topuz O, Ardıç F. Inmeli hastaların özellikleri ve fonksiyonel sonuçlarını etkileyen faktörler. J PMR Sci 2009;12:59-66.

29. Macciocchi SN, Diamond PT, Alves WM. Ischemic stroke: relation of age, lesion location, and initial neurologic deficit to functional outcome. Arch Phys Med Rehabil 1998;79:1255-7. [CrossRef]

30. Pantano P, Formisano R, Ricci M, Di Piero V, Sabatini U, Di Pofi B, et al. Motor recovery after stroke. Morphological and functional brain alterations. Brain 1996;119:1849-57. [CrossRef]
31. Paolucci S, Antonnucci G, Grasso MG, Morelli D, Troisi E, Coiro $P$, et al. Early versus delayed inpatient stroke rehabilitation: a matched comparison conducted in Italy. Arch Phys Med Rehabil 2000;81:695-700. [CrossRef]

32. Balcı B, Ertekin Ö, Kara B, Yaka E. Akut inme hastalarında hastane içi rehabilitasyon programının etkileri. Journal of Neurological Sciences (Turkish) 2011;27:142-54.

33. Indredavik B, Bakke F, Slørdahl SA, Rokseth R, Håheim LL. Treatment in a combined acute and rehabilitation stroke unit: which aspects are most ımportant? Stroke 1999;30:917-23. [CrossRef]

34. Karataş M, Yavuz N, Akman N, Kılınç Ş, Sözay S, Leblebicioğlu B, et al. Yaşlanma ve eşlik eden hastalıkların hemipleji rehabilitasyonu sonuçlarına etkisi: 104 hastada yapılan retrospektif bir çalışma. Geriatri 1998;1:24-8.

35. Paolucci S, Grasso M, Antonucci G, Bragoni M, Troisi E, Morelli D, et al. Mobility status after inpatient stroke rehabilitation; 1-year followup and prognostic factors. Arch Phys Med Rehabil 2001;82:2-8. [CrossRef]

36. Bardak AN, Ersoy S, Akcan Z, Kaya B, Dere Ç, Uysal E, et al. Yatarak rehabilite edilen inmeli hastaların fonksiyonel sonuçları. Türk Fiz Tıp Derg 2008;54:17-21.

37. Wang WY, Chang J], Sung YT, Lin YT. The relationship between functional recovery one year after a stroke and related factors. Gaoxiong Yi Xeu Ke Xue Za Zhi 1991;7:136-43. 